\title{
Safety and performance of cohesive polydensified matrix hyaluronic acid fillers with lidocaine in the clinical setting - an open-label, multicenter study
}

This article was published in the following Dove Press journal:

Clinical, Cosmetic and Investigational Dermatology

20 October 2016

Number of times this article has been viewed

\section{Ulrich Kühne' \\ Jørgen Esmann² \\ Dennis von Heimburg ${ }^{3}$ \\ Matthias Imhof' \\ Petra Weissenberger ${ }^{4}$ \\ Gerhard Sattler ${ }^{5}$ \\ On behalf of the BALIA \\ Study Group}

'Aesthetische Dermatologie im Medico Palais, Bad Soden, Germany; ${ }^{2}$ Jørgen Esmann Aps, Hellerup, Denmark; ${ }^{3}$ Praxisklinik Kaiserplatz,

Frankfurt am Main, Germany;

${ }^{4}$ Corporate Clinical Research, Merz

Pharmaceuticals $\mathrm{GmbH}$, Frankfurt

am Main, Germany; ${ }^{5}$ Rosenparkklinik

GmbH, Darmstadt, Germany
Correspondence: Gerhard Sattler Rosenparkklinik $\mathrm{GmbH}$, Heidelberger Landstraße, I8-20, 64297 Darmstadt, Germany

Tel +49 6I5I I5988383

Fax +496151 15988388

Email gerhard.sattler@rosenparkklinik.de

\begin{abstract}
Cohesive polydensified matrix $\left(\mathrm{CPM}^{\circledR}\right)$ hyaluronic acid fillers are now available with or without lidocaine. The aim of this study was to investigate the safety and performance of $\mathrm{CPM}^{\circledR}$ fillers with lidocaine in the clinical setting. In an open-label, prospective, postmarketing study, 108 patients from seven sites in Germany and Denmark were treated with one or more lidocaine-containing $\mathrm{CPM}^{\circledR}$ fillers. Performance was assessed using the Merz Aesthetics Scales ${ }^{\circledR}$ (MAS). Pain was rated on an 11-point visual analog scale. Patients' and physicians' satisfaction as well as adverse events were recorded. Improvements of $\geq 1$-point on MAS immediately after and 17 days posttreatment were observed in $\sim 90 \%$ of patients compared with baseline. All investigators assessed ejection force, product positioning, and performance as similar or superior to the respective nonlidocaine products. Overall, $94 \%$ of investigators were satisfied with the esthetic outcomes and were willing to continue using the products. All patients except one were satisfied with the results, and all were willing to repeat the treatment. Mean pain scores were low during $(<3.0)$ and after injection $(<0.6)$. Except for one case of bruising, all adverse events were mild to moderate. $\mathrm{CPM}^{\circledR}$ fillers with lidocaine are safe and effective for a wide range of esthetic facial indications.
\end{abstract}

Keywords: cohesive polydensified matrix, dermal fillers, Belotero, Esthélis, Fortélis, Modélis

\section{Introduction}

Interest in noninvasive and minimally invasive methods to model and to correct facial wrinkles has increased worldwide in the last few decades, such that they now comprise $>80 \%$ of all esthetic interventions, compared with $<50 \%$ in the 1990 s. $^{1}$ Dermal fillers are a common minimally invasive option for the nonpermanent treatment of age-related facial wrinkles, nasolabial folds (NLF), marionette lines, and cheek hollowness. ${ }^{2}$ Among the biodegradable filler products currently available, hyaluronic acid (HA) fillers are used most often because of their good performance and favorable safety profile. ${ }^{1}$

HA fillers with various degrees of cross-linking are highly elastic and viscous compared with noncross-linked HA and are thus very suitable as biologically compatible fillers for the treatment of lines and wrinkles. These fillers have been used successfully for many years for the temporary correction of facial wrinkles and folds, such as NLF.,4 They are also used to restore volume loss in the cheeks and the chin as well as to enhance lip fullness. ${ }^{5,6}$ The monophasic, cohesive polydensified matrix $\left(\mathrm{CPM}^{\circledR}\right)$ HA fillers (Belotero ${ }^{\circledR}$; Anteis S.A., Geneva, Switzerland, a wholly owned subsidiary of Merz Pharmaceuticals GmbH, Frankfurt am Main, Germany) are manufactured with a patented dynamic two-stage cross-linking technology, which results in cohesive gels with 
zones of various densities (low and highly cross-linked areas). ${ }^{7}$ These fillers have been shown to have soft flowing qualities, allowing for smooth injection, and a homogeneous pattern of tissue integration, resulting in favorable esthetic results. ${ }^{8,9}$

The Belotero ${ }^{\circledR}$ products have different HA concentrations (Soft: $20.0 \mathrm{mg} / \mathrm{mL}$; Basic/Balance: $22.5 \mathrm{mg} / \mathrm{mL}$; Intense: $25 \mathrm{mg} / \mathrm{mL}$; Modélis ${ }^{\circledR}$ [now available as Belotero ${ }^{\circledR}$ volume]: $26 \mathrm{mg} / \mathrm{mL}$ ) and cover a wide spectrum of esthetic needs from the treatment of fine, moderate, or deep wrinkles to lip augmentation and volume enhancement. This is achieved while complying with the essential features of a safe and effective filler: ease of use, comfort for patients during and after injection, good tolerability, and longevity of results. ${ }^{10}$ Belotero $^{\circledR} /$ Esthélis $^{\circledR}$ Soft Lidocaine (Soft-L) is indicated for the filling of fine lines (eg, perioral and forehead lines, crow's feet, lip commissures) and is injected into the superficial to mid-dermis. Belotero ${ }^{\circledR} /$ Esthélis $^{\circledR}$ Basic Lidocaine (Basic-L) provides lip enhancement and filling of moderate facial wrinkles and folds and is injected into the superficial to middermis. Fortélis ${ }^{\circledR}$ Extra/Belotero ${ }^{\circledR}$ Intense Lidocaine (Extra/ Intense-L) provides filling of folds and deep wrinkles as well as significant volume enhancement of the target areas (eg, contours of the face, lip volume) and is injected into the deep dermis. Modélis ${ }^{\circledR}$ Shape Lidocaine (Modélis-L) is indicated for the restoration of facial volume loss. It is injected into the deep subcutaneous layers or above the periosteum.

Available clinical data have demonstrated the performance and safety of the $\mathrm{CPM}^{\circledR}$ HA fillers when injected as per their respective instructions for use in specific areas of the face. ${ }^{4,6,11,12}$ However, there is little information on the performance and safety of these products when one or more is injected according to the patient's wishes and needs in multiple areas of the face in a single session. This study was therefore conceived to provide good-quality, postmarketing data from a large cohort on the safety and performance of $\mathrm{CPM}^{\circledR}$ HA fillers with lidocaine in the clinical setting.

\section{Materials and methods}

This was an open-label, multicenter, prospective, postmarketing, clinical follow-up study performed at seven sites in Germany and Denmark. The study was conducted in accordance with the Declaration of Helsinki and reviewed and approved by the respective independent ethic committees in Germany and Denmark (Ethik-Kommission bei der Landesaerztekammer Hessen, Frankfurt, Germany; Center for Sundhed, De Videnskapsetiske Komiteer Region Hovedstaden, Hillerød, Denmark). All patients provided written informed consent before enrollment in the study. All the HA fillers were CE marked and were used as per labeling.
In Germany, the products used were Belotero ${ }^{\circledR}$ Soft-L, Belotero ${ }^{\circledR}$ Basic-L, and Belotero ${ }^{\circledR}$ Intense-L. In Denmark, the HA fillers were Esthélis ${ }^{\circledR}$ Soft-L, Esthélis ${ }^{\circledR}$ Basic-L, Fortélis ${ }^{\circledR}$ Extra-L, and Modélis-L. Belotero ${ }^{\circledR}$ and Esthélis ${ }^{\circledR} /$ Fortélis $^{\circledR}$ product lines have identical galenic forms, presentations, composition, and administration routes. Modélis-L was not marketed in Germany at the time of the study; therefore, this product was evaluated only in Denmark.

The primary objective of the study was to collect clinical data on the $\mathrm{CPM}^{\circledR}$ family of products with lidocaine (Soft-L, Basic-L, Extra/Intense-L, and Modélis-L) immediately after injection. Secondary objectives were to assess the safety and performance of the HA fillers 17 days ( \pm 3 days) postinjection and to evaluate these parameters in comparison to the same range of products without lidocaine.

A total of 108 patients seeking esthetic treatment in the face were recruited from the investigators' patient pool. Prior to treatment at the first visit (V1), patients' baseline characteristics were documented, and a severity assessment of the area to be treated was performed using the appropriate 5-point Merz Aesthetics Scales ${ }^{\circledR}$ (MAS). ${ }^{13-15}$ During this visit, the patients were treated in one or more areas of the face with the $\mathrm{CPM}^{\circledR} \mathrm{HA}$ filler(s) selected by the investigator according to their usual practice and patients' needs. The volume to be injected (up to a total of $8 \mathrm{~mL}$ ) and the injection techniques were at the investigator's discretion. At a follow-up visit 17 days ( \pm 3 days) postinjection (V2), further assessments were performed, including optional touch-up injections, if required, in which case the same product as the one injected at V1 was used. The V2 follow-up visit coincided with the routine patient follow-up performed in clinical practice, typically scheduled for $\sim 2$ weeks after initial treatment.

All evaluations at a given site were carried out by the same investigator. Performance was assessed at rest using the MAS at V1 (preinjection and immediately postinjection) and at V2. In case of a touch-up injection at V2, the evaluation was performed prior to injection(s). For bilateral treatment, each side was scored separately. A score decrease in MAS means improvement, except for the lip fullness MAS, where higher values correspond to improvement in lip fullness. Changes in MAS scores were calculated as follows: the patients' baseline scores minus the respective postinjection scores at V1 and preinjection scores at V2, whereas the reverse was done for upper and lower lips. This approach was necessary to display changes consistently as positive changes in case of improvement.

Patients' satisfaction was assessed at V1 postinjection and at V2 pretouch-up using a three-item questionnaire. Investigators' satisfaction with the product was assessed after the last patient of the site completed the study using a questionnaire 
that included ease of injection, distribution and positioning of the fillers in the skin, esthetic outcomes in comparison to similar competitor products, performance in comparison to Belotero ${ }^{\circledR} /$ Esthélis ${ }^{\circledR}$ products without lidocaine, and willingness to continue treating patients with the fillers tested. Only one questionnaire was completed per site and investigator.

Safety evaluation included the analysis of adverse events (AEs), patient pain rating with an 11-point visual analog scale ranging from " 0 " (= no pain) to " 10 " (= extreme pain), and local tolerability to the injections during each visit using the injection-site reaction (ISR) scale. All ISRs were considered treatment-emergent adverse events (TEAEs).

\section{Statistical methods}

The analyses were descriptive based on observed cases and, when appropriate, were reported by the filler used and by indication. Continuous variables were summarized by number, mean, SD, median, minimum, and maximum. For qualitative variables, absolute and percent frequencies $(\mathrm{N}, \%)$ were calculated.

\section{Results}

\section{Demographics}

A total of 108 patients (102 women) were enrolled between May and July 2014 at five sites in Germany and two sites in Denmark. Mean age was 47.1 years (range: 23-78 years). The vast majority $(98.1 \%)$ of patients were Caucasian. The severity scores in MAS for each facial area at V1 preinjection are presented in Table 1.

\section{Indications and products used}

The most frequently treated facial areas were the NLF in $81(75.0 \%)$ patients, mainly injected with Extra/Intense-L, followed by the marionette lines in $41(38.0 \%)$ patients, injected with Basic-L or Extra/Intense-L, and the upper cheek in $38(35.2 \%)$ patients, mostly injected with Extra/
Intense-L (Table 2). Oral commissures and upper lips were treated in $26(24.1 \%)$ and $25(23.1 \%)$ patients, respectively, mainly with Basic-L or Extra/Intense-L. Overall, 18 (16.7\%) patients received Soft-L, 72 (66.7\%) received Basic-L, 86 (79.6\%) received Extra/Intense-L, and six (5.6\%) received Modélis-L. In total, 78 patients received treatment in multiple areas with one or different products (including three patients with touch-up injections). Nineteen patients were treated with different products combined in the same area, whereas the remaining 59 patients were treated with one or several products but in different areas.

The mean overall volume injected per patient at V1 was $3.4 \mathrm{~mL}$ (range: $0.5-8.0 \mathrm{~mL}$ ). As expected, volumizing indications required larger amounts of filler than the filling of fine wrinkles, and larger volumes of Extra/Intense-L and Modélis-L were administered (mean volumes: $2.5 \mathrm{~mL}$ and $3.3 \mathrm{~mL}$, respectively, for both sides) in comparison to Soft-L and Basic-L. Sixteen patients received touch-up injections at V2, with a mean volume of $1.0 \mathrm{~mL}$ (range: $0.4-2.0 \mathrm{~mL}$ ), differing for the facial regions and side of the face treated (single or both).

Soft-L was injected according to the instructions for use into the superficial to mid-dermis in $83.3 \%$ of patients. Basic-L and Extra/Intense-L were administered at all

Table I Mean Merz Aesthetics Scale ${ }^{\circledR}$ (MAS) scores at visit I preinjection by treatment area

\begin{tabular}{ll}
\hline Facial area & MAS scores \\
\hline Upper cheek & $2.65 \pm 0.88$ \\
Lower cheek & $2.86 \pm 0.95$ \\
Nasolabial fold & $2.30 \pm 0.84$ \\
Marionette lines & $2.39 \pm 0.82$ \\
Upper lip & $1.16 \pm 0.69$ \\
Lower lip & $1.17 \pm 0.62$ \\
Lip wrinkles & $2.56 \pm 0.86$ \\
Oral commissures & $2.15 \pm 0.92$ \\
\hline
\end{tabular}

Note: Data are presented as mean \pm standard deviation.

Table 2 Facial areas by products used

\begin{tabular}{|c|c|c|c|c|c|c|c|c|c|c|}
\hline \multirow[t]{2}{*}{ Facial area } & \multicolumn{2}{|c|}{ Soft-L, $N=18$} & \multicolumn{2}{|c|}{ Basic-L, $N=72$} & \multicolumn{2}{|c|}{ Extra/Intense-L, $N=86$} & \multicolumn{2}{|c|}{ Modélis-L, N=6 } & \multicolumn{2}{|c|}{ Total, $\mathbf{N}=108$} \\
\hline & $\mathbf{n}$ & $\%$ & $\mathbf{n}$ & $\%$ & $\mathbf{n}$ & $\%$ & $\mathbf{n}$ & $\%$ & $\mathbf{n}$ & $\%$ \\
\hline Upper cheek & 0 & 0.0 & 2 & 5.3 & 32 & 84.2 & 6 & 15.8 & $38^{\mathrm{a}}$ & 35.2 \\
\hline Lower cheek & 4 & 28.6 & 9 & 64.3 & 6 & 42.9 & 0 & 0.0 & $14^{\mathrm{a}}$ & 13.0 \\
\hline Nasolabial fold & 1 & 1.2 & 29 & 35.8 & 67 & 82.7 & 0 & 0.0 & $81^{a}$ & 75.0 \\
\hline Marionette lines & 0 & 0.0 & 22 & 53.7 & 21 & 51.2 & 0 & 0.0 & $4 I^{a}$ & 38.0 \\
\hline Upper lip & I & 4.0 & 18 & 72.0 & 9 & 36.0 & 0 & 0.0 & $25^{\mathrm{a}}$ & 23.1 \\
\hline Lower lip & 0 & 0.0 & 15 & 83.3 & 3 & 16.7 & 0 & 0.0 & 18 & 16.7 \\
\hline Lip wrinkles & 13 & 72.2 & 5 & 27.8 & 1 & 5.6 & 0 & 0.0 & $18^{\mathrm{a}}$ & 16.7 \\
\hline Oral commissures & 1 & 3.8 & 14 & 53.8 & 11 & 42.3 & 0 & 0.0 & 26 & 24.1 \\
\hline
\end{tabular}

Notes: $\mathrm{N}$, overall number of patients who were treated with the specific product; $n$, number of patients who received the product for the specific facial area. ${ }^{\text {Some }}$ patients received more than one product for the same facial area.

Abbreviations: Soft-L, Soft Lidocaine; Basic-L; Basic Lidocaine; Extra/Intense-L, Extra/Intense Lidocaine; Modélis-L, Modélis ${ }^{\circledR}$ Shape Lidocaine. 
possible depths (superficial to mid-dermis, deep dermis, subcutaneous, and upper periosteum). Modélis-L was injected subcutaneously in $100 \%$ of patients.

\section{Performance}

The vast majority of patients ( $90 \%)$ showed an improvement of at least 1 and up to 3 points in MAS for the treated facial area compared with the scores at V1 preinjection. The highest percentage of responders (patients with $\geq 1$-point improvement in MAS) was observed for the lip area, ie, upper and lower lips and lip wrinkles (100\% at V1 and $89 \%-96 \%$ at V2), followed by the NLF, upper cheeks, and marionette lines (94\%-97\% at V1 and 86\%-95\% at V2). The lowest percentage of responders was observed for the lower cheeks and oral commissures (92\%-93\% at V1 and $85 \%-89 \%$ at V2).

Overall, the highest mean changes were observed for the upper lip (mean improvement on MAS of 1.76 at V1 and 1.56 at V2) and the lower cheek (mean improvement on MAS of 1.71 at both visits). It should be noted that swelling of the lips is common immediately after injection, and therefore, the V2 score may give a better measure of real treatment effect in this area. The lowest mean changes were observed for the oral commissures (mean improvement in MAS of 1.23 at V1 and 1.08 at V2) and the marionette lines (mean improvement in MAS of 1.24 at V1 and 1.30 at V2).

Assessment by product showed that, for patients treated with Soft-L, the mean improvement in MAS compared with preinjection scores for lip wrinkles, ie, perioral lines $(n=13)$, was 1.85 at V1 and 1.54 at V2, and for lower cheek $(n=4)$ was 1.00 at both visits (Figure 1).
The mean improvement in MAS in patients treated with Basic-L ranged between 1.21 and 1.67 at $\mathrm{V} 1$ and between 0.93 and 1.56 at $\mathrm{V} 2$, depending on the facial region treated (Figure 2). An exception was the upper cheek region in one patient, who showed a mean improvement in MAS of 2.00 at $\mathrm{V} 1$ and 3.00 at V2. The lowest mean change was documented for the oral commissures (1.29 at V1 and 0.93 at V2).

Treatment of patients with Extra/Intense-L resulted in mean changes between 1.00 and 2.11 at $\mathrm{V} 1$ and between 1.00 and 2.00 at V2 (Figure 3). The highest mean changes were recorded for the upper lip (2.11 at V1 and 1.89 at V2), lower lip, and lower cheek (2.00 at both visits and in both treatment areas), and the lowest mean changes were seen for lip wrinkles (1.00 at both visits).

Modélis-L was only used to treat the upper cheek in six patients, and the mean improvement on MAS for this region was 1.67 at V1 and 2.17 at V2 (Figure 4).

\section{Pain}

Pain during injection was documented 228 times. On an 11 -point visual analog scale ranging from " 0 " (= no pain) to "10" (= extreme pain), the mean overall pain score was 2.9 for Soft-L (19 records), 3.0 for Basic-L ( 88 records), 2.9 for Extra/ Intense-L (115 records), and 1.8 for Modélis-L (six records). Pain scores during injection were higher in sensitive areas, ie, lower lip (mean score of 4.3), marionette lines (mean score of 3.6), and upper lip (mean score of 3.4). Pain immediately after injection was documented 198 times. However, the mean overall pain scores were very low $(<1.0)$ : 0.4 for Soft-L (19 records), 0.6 for Basic-L (79 records), 0.4 for Extra/Intense-L (94 records), and 0.0 for Modélis-L (six records).

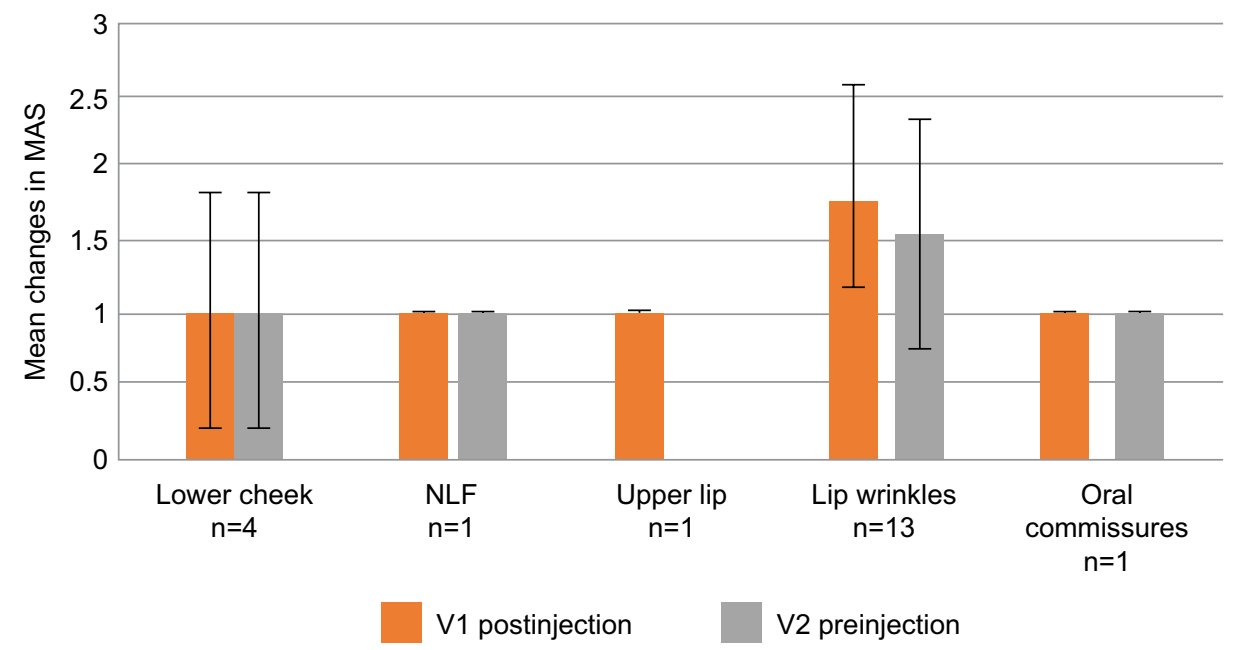

Figure I Mean improvements on Merz Aesthetics Scales ${ }^{\circledR}$ (MAS) compared with baseline scores at VI (postinjection) and V2 (preinjection) by treated area for Soft-L. Abbreviations: Soft-L, Soft Lidocaine; NLF, nasolabial folds. 


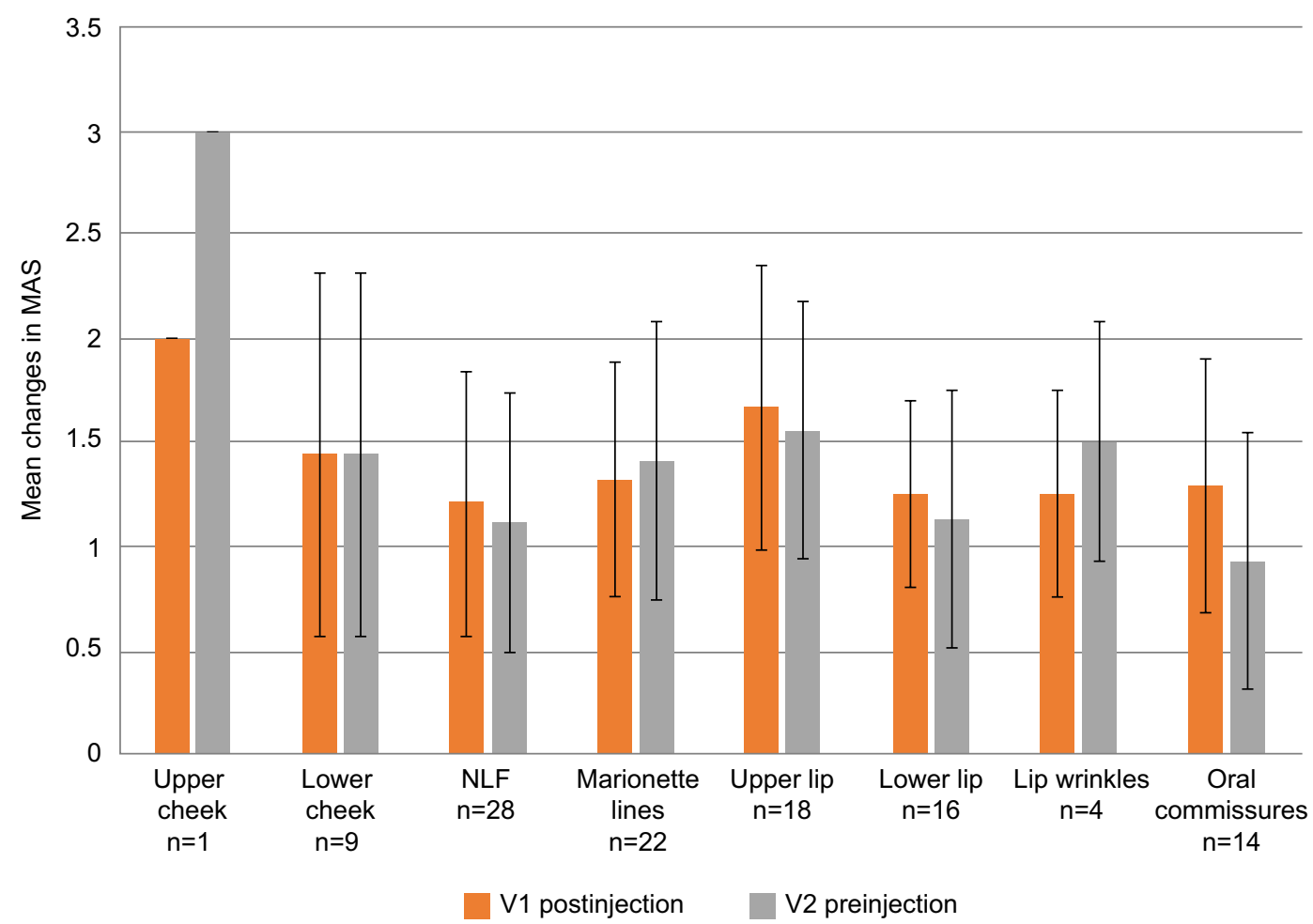

Figure 2 Mean improvements on Merz Aesthetics Scales ${ }^{\circledR}$ (MAS) compared with baseline scores at VI (postinjection) and V2 (preinjection) by treated area for Basic-L. Abbreviations: Basic-L; Basic Lidocaine; NLF, nasolabial folds.

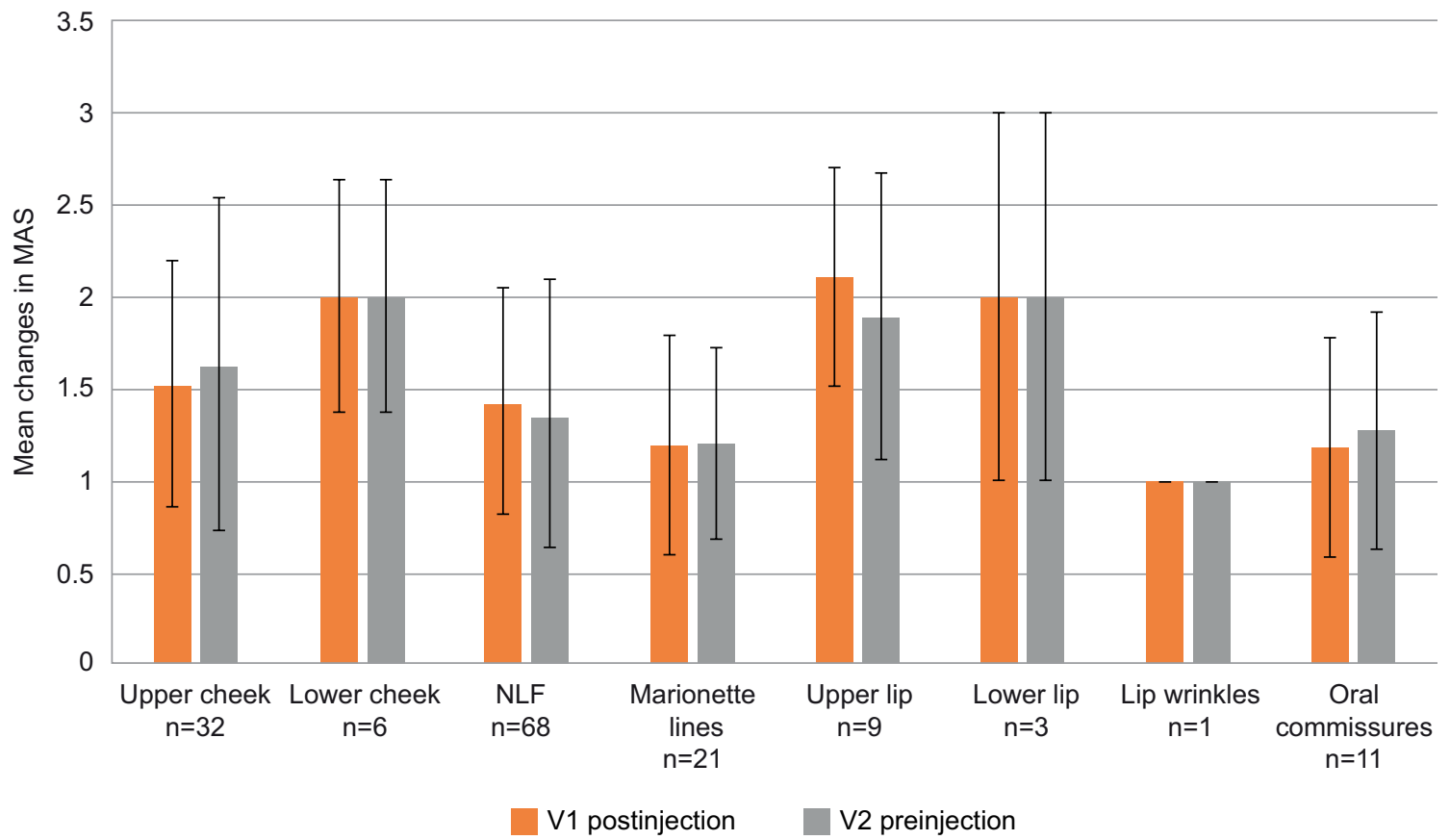

Figure 3 Mean improvements on Merz Aesthetics Scales ${ }^{\circledR}$ (MAS) compared with baseline scores at VI (postinjection) and V2 (preinjection) by treated area for Extra/ Intense-L.

Abbreviations: Extra/Intense-L, Extra/Intense Lidocaine; NLF, nasolabial folds.

\section{Patients' satisfaction}

At V1 postinjection, all patients were satisfied with the treatment results, were willing to repeat the treatment, and to recommend it to their friends/families. One patient was lost to follow-up (missed V2 due to vacation). At V2, the remaining 107 patients were satisfied with the treatment results (except one), and all 107 were willing to repeat the treatment and to recommend it to their friends/families. 


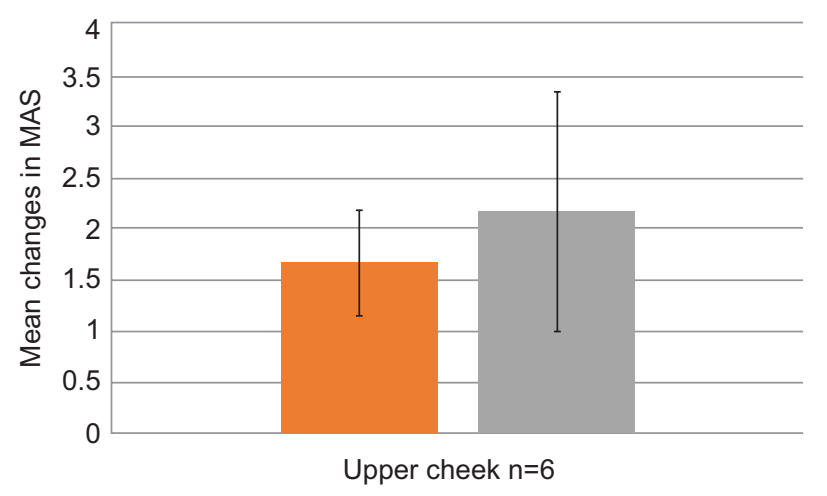

V1 postinjection

V2 preinjection

Figure 4 Mean improvements on Merz Aesthetics Scales ${ }^{\circledR}$ (MAS) compared with baseline scores at VI (postinjection) and V2 (preinjection) by treated area for Modélis-L.

Abbreviation: Modélis-L, Modélis $®$ Shape Lidocaine.

\section{Investigators' satisfaction}

All but one investigator assessed ease of injection as "easy" or "very easy", and all assessed the ejection force as identical, similar, or easier than the respective nonlidocaine product. The distribution and positioning of the product in the skin were rated as either "very satisfying" (58.8\%) or "rather satisfying" ( $41.2 \%)$ by all investigators. The performance of the lidocaine-containing fillers, in comparison to the Belotero ${ }^{\circledR} /$ Esthélis $^{\circledR}$ range without lidocaine, was rated as identical, similar, or better by all investigators; five investigators rated it as "better". The vast majority (94.1\%) of investigators judged the esthetic outcomes of the fillers tested as equivalent, similar, or better to the results obtained with comparable competitors' products. When compared with the respective nonlidocaine product, $64.7 \%$ of the investigators rated the pain felt by the patient during the injection as "less disturbing" and $82.4 \%$ rated the pain felt by the patient after treatment as "less disturbing". Most investigators (82.4\%) were willing to continue treating their patients with the fillers tested, and $11.8 \%$ would do so to a certain extent.

\section{Safety}

No serious AEs, AEs leading to discontinuation, or fatal AEs were reported. Fifty-two (48.1\%) of 108 patients experienced at least one TEAE. All TEAEs $(\mathrm{n}=212)$ were treatment related and restricted to the injection area (Table 3). All TEAEs were of mild or moderate intensity, except one case of severe injection-site bruising reported in one patient after treatment with Extra/Intense-L for NLF, who fully recovered after 10 days. No necrosis or infection at the injection site was observed.

At V1, the most common ISRs were redness (113 events), swelling ( 82 events), and bruising ( 25 events), followed by coloration (11 events) and firmness (five events). At V2 before touch-up, the ISRs reported were bruising (six events) and swelling (five events). At V2 after touch-up, redness was reported three times, swelling three times, and bruising only once. The majority of ISRs were mild or moderate and transient in duration.

\section{Discussion}

This was a multicenter, observational study in a clinical setting using four different $\mathrm{CPM}^{\circledR} \mathrm{HA}$ fillers with lidocaine. The study included 108 patients and reflected normal clinical practice in that there were no restrictions to the areas treated, and the choice of filler or their combination was at the investigators' discretion according to the patients' needs.

The study confirms the good performance and safety of $\mathrm{CPM}^{\circledR}$ HA fillers with added lidocaine for a range of facial indications in routine clinical practice. The majority of patients ( $\sim 90 \%)$ showed an improvement of at least 1 point on MAS immediately after injection and 2.5 weeks posttreatment, when compared with baseline. Only a few patients had unchanged postinjection ratings, and there was no worsening of the MAS rating for any patient in any treatment group.

Table 3 Treatment-emergent adverse events by products used

\begin{tabular}{|c|c|c|c|c|c|c|c|c|c|c|c|c|c|c|c|}
\hline \multirow[t]{2}{*}{ TEAE } & \multicolumn{3}{|c|}{ Soft-L $(N=18)$} & \multicolumn{3}{|c|}{ Basic-L (N=72) } & \multicolumn{3}{|c|}{ Extra/Intense-L $(\mathrm{N}=86)$} & \multicolumn{3}{|c|}{ Modélis-L $(\mathrm{N}=6)$} & \multicolumn{3}{|c|}{ Total $(\mathrm{N}=108)$} \\
\hline & $\bar{n}$ & $\%$ & $\overline{\mathbf{m}}$ & $\bar{n}$ & $\%$ & $\overline{\mathbf{m}}$ & $\bar{n}$ & $\%$ & $\mathbf{m}$ & $\bar{n}$ & $\%$ & $\bar{m}$ & $\bar{n}$ & $\%$ & $\bar{m}$ \\
\hline Patients with $\geq$ I TEAE & 8 & 44.4 & 11 & 36 & 50.0 & 84 & 41 & 47.7 & 114 & 2 & 33.3 & 3 & 52 & 48.1 & 212 \\
\hline Injection-site erythema & 4 & 22.2 & 4 & 29 & 40.3 & 43 & 36 & 41.9 & 55 & 0 & 0.0 & 0 & 45 & 41.7 & 102 \\
\hline Injection-site swelling & 2 & 11.1 & 2 & 20 & 27.8 & 29 & 25 & 29.1 & 42 & 2 & 33.3 & 2 & 36 & 33.3 & 75 \\
\hline Injection-site bruising & 3 & 16.7 & 3 & 7 & 9.7 & 10 & 7 & 8.1 & 10 & 1 & 16.7 & I & 14 & 13.0 & 24 \\
\hline Injection-site discoloration & 1 & 5.6 & 2 & 2 & 2.8 & 2 & 2 & 2.3 & 3 & 0 & 0.0 & 0 & 3 & 2.8 & 7 \\
\hline Injection-site induration & 0 & 0.0 & 0 & 0 & 0.0 & 0 & 3 & 3.5 & 4 & 0 & 0.0 & 0 & 3 & 2.8 & 4 \\
\hline
\end{tabular}

Note: $n$, number of patients who experienced $\geq$ I TEAE; $m$, number of TEAEs.

Abbreviations: Soft-L, Soft Lidocaine; Basic-L; Basic Lidocaine; Extra/Intense-L, Extra/Intense Lidocaine; Modélis-L, Modélis ${ }^{\circledR}$ Shape Lidocaine; TEAE, treatment-emergent adverse event. 
The percentage of responders (patients with $\geq 1$-point improvement on MAS) was high for all facial areas, but was greatest for the lip area, followed by the NLF, upper cheeks, and marionette lines, and finally the lower cheeks and oral commissures. Depending on the facial region treated, mean improvements on MAS ranged from $1.0-1.85$ at V1 and 1.0-1.54 at V2 for Soft-L, from 1.21-2.0 at V1 and 0.93-3.0 at V2 for Basic-L, and 1.0-2.11 at V1 and 1.0-2.0 at V2 for Extra/Intense-L.

In this study, filler selection was at the discretion of the investigator, and with the exception of Modélis-L, all fillers were used for a variety of indications. Although there is some overlap, the four $\mathrm{CPM}^{\circledR} \mathrm{HA}$ fillers have been developed for specific purposes. The different areas of the face vary in their underlying structures, requiring different product characteristics, injection volumes, and injection techniques. Best results were observed when each filler was used for its preferred indication, eg, lip wrinkles for Soft-L and cheek volumization, NLF correction, and lip augmentation for Extra/Intense-L. Basic-L showed improvements in the widest range of indications, illustrating its substantial versatility. In this study, Modélis-L was used in six patients for upper cheek volumizing with mean improvements in MAS of 1.67 at V1 and 2.17 at $\mathrm{V} 2$. The limited number of patients treated is due to the fact that Modélis-L was not marketed in Germany at the time of the study and was therefore only evaluated at sites in Denmark.

The overall range of mean improvement for all treated areas (1.08-1.76) was similar to the improvements reported on a 5-point scale in the literature: mean improvement of 1.6 points for perioral lines, ${ }^{16} 1.5$ for $\mathrm{NLF}^{3}{ }^{3} 1.9$ for deep lines and wrinkles, ${ }^{9}$ and 1.5 for infraorbital hollow. ${ }^{12}$ No published data on the mean improvement for marionette lines, which was the second most common indication in this study $(n=41$, $38 \%$ ), with similar products were found.

There is little information in the literature concerning the injection of HA fillers in multiple areas of the face in a single session or layering fillers in the same area. In this study, 19 patients were treated with different products combined in the same area, whereas the remaining 59 patients were treated with one or several products, but in different areas. In both cases, the efficacy and safety of $\mathrm{CPM}^{\circledR}$ fillers were confirmed. A previous study that used the so-called "sandwich technique" to layer non-lidocaine $\mathrm{CPM}^{\circledR}$ fillers - with the higher density product Extra/Intense injected in the deep dermis and Basic more superficially - reported treatment effects to be additive and well tolerated. ${ }^{9}$
Overall, patient satisfaction is a key parameter when evaluating the performance of dermal fillers, since esthetic interventions are optional, and the patients play a decisive role in treatment choice. In this study, all patients were willing to repeat the treatment and to recommend it to friends/family. This corroborates the findings of several publications that show good patient outcomes, immediate results, and high satisfaction when using HA fillers for treatment of lines and wrinkles $^{16,17}$ and for volume restoration..$^{6,18}$

The mean overall injected volume $(3.4 \mathrm{~mL})$ at $\mathrm{V} 1$ was markedly lower than the $8 \mathrm{~mL}$ allowed per patient. The high patient satisfaction and the ease of injection reported by the investigators indicate that the relatively low volumes injected were not due to difficulties in injecting higher volumes but that volumes of $<8 \mathrm{~mL}$ were sufficient for optimal esthetic outcomes. In clinical practice, patients usually seek subtle improvements that do not modify their overall appearance too much, and therefore, physicians do not target improvements of $>2$ points in MAS. The volume efficiency of the $\mathrm{CPM}^{\circledR} \mathrm{HA}$ fillers can be explained by their optimal rheological properties and homogeneous pattern of tissue integration after intra- or subdermal implantation. $.6,8,11,19,20$

The investigators assessed the pain felt by the subjects as being less than or similar to the pain felt when using nonlidocaine products, thus underlining the added benefit of including lidocaine in the dermal filler formulation (less pain and more comfort for the patients). The low pain scores during injection and very low pain scores after injection reported by the patients were similar to published pain assessments of fillers with lidocaine, whereas products without lidocaine lead to higher pain scores on an 11-point scale. ${ }^{17,21,22}$ The low pain scores during injection might be the result of the enhancing effect of the added lidocaine to the intrinsically lower pain generating composition of the monophasic $\mathrm{CPM}^{\circledR}$ fillers, as shown in the study of Buntrock et al. ${ }^{4}$ The even lower pain scores after injection could be explained by the lag time until lidocaine exerts its full anesthetic effect, as suggested by Moradi et al..$^{23}$

The data collected during this study support the good safety profile of the $\mathrm{CPM}^{\circledR}$ HA fillers. The minor ISRs reported, such as redness, swelling, and bruising, are to be expected with any type of dermal filler injection and are usually temporary. ${ }^{16,24-26}$ The highest percentage of patients with at least one TEAE was reported for the oral commissures (65.4\%) and the lowest percentages were observed for the upper (20.0\%) and lower lip (27.8\%). Since this study was not designed to find a correlation with any particular parameter, 
these results could be linked to the smaller volumes injected into the lips, the product used, the injector's experience, the vessel supply in the treated area, the injection technique, and/ or the speed of injection. The follow-up period of $17 \pm 3$ days was chosen because ISRs are likely to occur either immediately after injection or within about 2 weeks following the procedure. ${ }^{25}$ Any ISRs and AEs typical for HA fillers would have been documented within the follow-up period and unexpected AEs or delayed reactions, that can occur up to several months after treatment, ${ }^{25}$ would have been monitored by the manufacturer's medical device vigilance system.

This is the first study in a clinical setting to evaluate the lidocaine-containing $\mathrm{CPM}^{\circledR} \mathrm{HA}$ fillers in regular clinical practice: treatment of different and selected areas of the face in one session, according to the patients' wishes and physicians' judgment. In this context, the positive results and the good safety profile of the $\mathrm{CPM}^{\circledR} \mathrm{HA}$ fillers demonstrate the importance of the investigators' experience and the suitability of the fillers tested for comprehensive facial treatments in a normal clinical setting.

Limitations of this study were the small number of patients in some of the treatment groups and the relatively short follow-up time. Nevertheless, the results reflect the "real-life" conditions under which the fillers are used in daily practice in two European countries.

\section{Conclusion}

This study confirms the safety and performance of the $\mathrm{CPM}^{\circledR}$ range of HA fillers with lidocaine for a variety of treatment indications in the clinical setting. Esthetic improvements related to facial wrinkles/folds, facial volume loss, and/or lip fullness were reported by the investigators for the vast majority of patients. The patients themselves reported a high level of satisfaction with the esthetic results and low level of discomfort during the procedures. Pain during and after injection was lower than that with the respective $\mathrm{CPM}^{\circledR} \mathrm{HA}$ fillers without lidocaine, and the majority of investigators rated the performance as equivalent or superior to the results obtained with competitor products and the nonlidocaine range. All AEs and ISRs were expected, nonserious, transient events restricted to the injection site and caused by the injection procedure itself. Overall, the study demonstrates the suitability of the Belotero ${ }^{\circledR} /$ Esthélis ${ }^{\circledR}$ family of products with lidocaine for comprehensive esthetic facial treatments in a daily clinical setting.

\section{Acknowledgments}

The authors would like to thank all investigators of the BALIA Study, Christine Kliebe-Frisch (Clinical Study
Manager) and Moritz Heinz (Biostatistician) for assistance in conducting and evaluating the study. This study was sponsored by Merz Pharmaceuticals GmbH, Frankfurt am Main, Germany. The sponsor was involved in designing and conducting the study; in the collection, analysis, and interpretation of data; and in the preparation of this manuscript.

\section{Disclosure}

Ulrich Kühne has acted as a speaker for Merz, Galderma, and Procutis and has conducted clinical trials for Merz. Jørgen Esmann reports no conflicts of interest in this work. Dennis von Heimburg has acted as a speaker and consultant for Merz. Matthias Imhof has acted as a consultant, speaker, and investigator in clinical trials for Merz. Petra Weissenberger is an employee of Merz. Gerhard Sattler has acted as a speaker for Merz, Allergan, and Galderma, and the Rosenparkklinik has received research support and has conducted clinical trials for Merz, Galderma, and Allergan. The authors report no other conflicts of interest in this work.

\section{References}

1. Cohen JL, Dayan S, Brandt FS, et al. Systematic review of clinical trials of small- and large-gel-particle hyaluronic acid injectable fillers for aesthetic soft tissue augmentation. Dermatol Surg. 2013;39(2):205-231.

2. Lorenc ZP, Fagien S, Flynn TC, Waldorf HA. Review of key Belotero Balance safety and efficacy trials. Plast Reconstr Surg. 2013;132(4 suppl 2):33S-40S.

3. Prager W, Wissmueller E, Havermann I, et al. A prospective, split-face, randomized, comparative study of safety and 12-month longevity of three formulations of hyaluronic acid dermal filler for treatment of nasolabial folds. Dermatol Surg. 2012;38(7 pt 2):1143-1150.

4. Buntrock H, Reuther T, Prager W, Kerscher M. Efficacy, safety, and patient satisfaction of a monophasic cohesive polydensified matrix versus a biphasic nonanimal stabilized hyaluronic acid filler after single injection in nasolabial folds. J Dermatol Surg. 2013;39(7):1097-1105.

5. Micheels P. Fortélis extra resorbable and non-surgical volumising implant of Swiss conception. J Cosmet Surg Med. 2011;6: $30-34$.

6. Micheels P, Ascher B, Beilin G, et al. Évaluation clinique de l'efficacité et l'innocuité d'un acide hyaluronique volumateur de technologie $\mathrm{CPM}^{\circledR}$ pour le traitement de multiples zones du visage [Clinical evaluation of the efficacy and safety of a volumizing hyaluronic acid with CPM technology for the treatment of multiple areas of the face]. Realités Thérapeutiques en Dermato-Vénérologie. 2014;235:1-8.

7. Gregory I. A study of the clinical effectiveness of a new polydensified monophasic hyaluronic acid dermal filler. $J$ Cosmet Surg Med. 2007;3:32-34.

8. Sundaram H, Cassuto D. Biophysical characteristics of hyaluronic acid soft-tissue fillers and their relevance to aesthetic applications. Plast Reconstr Surg. 2013;132(4 suppl 2):5S-21S.

9. Pavicic T. Efficacy and tolerability of a new monophasic, double-crosslinked hyaluronic acid filler for correction of deep lines and wrinkles. J Drugs Dermatol. 2011;10(2):134-139.

10. Gold M. The science and art of hyaluronic acid dermal filler use in esthetic applications. J Cosmet Dermatol. 2009;8(4):301-307.

11. Hevia O, Cohen BH, Howell DJ. Safety and efficacy of a cohesive polydensified matrix hyaluronic acid for the correction of infraorbital hollow: an observational study with results at 40 weeks. J Drugs Dermatol. 2014;13(9):1030-1036. 
12. Wollina U. Improvement of tear trough by monophasic hyaluronic acid and calcium hydroxylapatite. J Clin Aesthet Dermatol. 2014;7(10): 38-43.

13. Carruthers A, Carruthers J, Hardas B, et al. A validated grading scale for marionette lines. Dermatol Surg. 2008;34(suppl 2):S167-S172.

14. Carruthers J, Flynn TC, Geister TL, et al. Validated assessment scales for the mid face. Dermatol Surg. 2012;38(2 Spec No):320-332.

15. Narins RS, Carruthers J, Flynn TC, et al. Validated assessment scales for the lower face. Dermatol Surg. 2012;38(2 Spec No.):333-342.

16. Fabi SG, Champagne JP, Nettar KD, et al. Efficacy and safety of and patient satisfaction with injectable hyaluronic acid with $0.3 \%$ lidocaine hydrochloride for the treatment of superficial perioral lines or superficial lateral canthal lines. Dermatol Surg. 2013;39:1613-1620.

17. Philipp-Dormston WG, Hilton S, Nathan M. A prospective, openlabel, multicenter, observational, postmarket study of the use of a 15 $\mathrm{mg} / \mathrm{mL}$ hyaluronic acid dermal filler in the lips. $J$ Cosmet Dermatol. 2014;13:125-134.

18. Muhn C, Rosen N, Solish N, et al. The evolving role of hyaluronic acid fillers for facial volume restoration and contouring: a Canadian overview. Clin Cosmet Investig Dermatol. 2012;5:147-158.

19. Goh AS, Kohn JC, Rootman DB, Lin JL, Goldberg RA. Hyaluronic acid gel distribution pattern in periocular area with high-resolution ultrasound imaging. Aesthet Surg J. 2014;34:510-515.
20. Tran C, Carraux P, Micheels P, Kaya G, Salomon D. In vivo bio-integration of three hyaluronic acid fillers in human skin: a histological study. Dermatology. 2014;228:47-54.

21. Prager W, Micheels P. A prospective, comparative survey to investigate practitioners' satisfaction with a cohesive, polydensified-matrix ${ }^{\circledR}$, hyaluronic acid-based filler gel with and without lidocaine for the treatment of facial wrinkles. J Cosmet Dermatol. 2015;14:124-129.

22. Royo de la Torre J, Moreno-Moraga J, Isarria MJ, et al. The evaluation of hyaluronic acid, with and without lidocaine, in the filling of nasolabial folds as measured by ultrastructural changes and pain management. $J$ Drugs Dermatol. 2013;12(3):e46-e52.

23. Moradi A, Shirazi A, Moradi-Poehler J, Turner J, Howell DJ. A blinded, randomized, split-face pilot study of bruising and pain with hyaluronic acid for correction of perioral lines using no lidocaine, lidocaine alone, and lidocaine and epinephrine. Aesthet Surg J. 2015;35:443-455.

24. Micheels P, Vandeputte J, Kravtsov M. Treatment of age-related midface atrophy by injection of cohesive polydensified matrix hyaluronic acid volumizer. J Clin Aesthet Dermatol. 2015;8(3):28-34.

25. Funt D, Pavicic T. Dermal fillers in aesthetics: an overview of adverse events and treatment approaches. Clin Cosmet Investig Dermatol. 2013;6:295-316.

26. Sherman RN. Avoiding dermal filler complications. Clin Dermatol. 2009;27(suppl):S23-S32.
Clinical, Cosmetic and Investigational Dermatology

\section{Publish your work in this journal}

Clinical, Cosmetic and Investigational Dermatology is an international, peer-reviewed, open access, online journal that focuses on the latest clinical and experimental research in all aspects of skin disease and cosmetic interventions. This journal is included on PubMed. The manuscript management system is completely online

\section{Dovepress}

and includes a very quick and fair peer-review system, which is all easy to use. Visit http://www.dovepress.com/testimonials.php to read real quotes from published authors 